\title{
CORRIGENDUM
}

\section{Adaptive evolution of a key phytoplankton species to ocean acidification}

Kai T. Lohbeck, Ulf Riebesell and Thorsten B. H. Reusch

Nature Geoscience 5, 346-351 (2012); published online 08 April 2012; corrected after print 20 November 2012.

In the version of this article originally published, the $y$ axis scales of Fig. $3 \mathrm{c}-\mathrm{f}$ were incorrect. This has been corrected in the PDF and HTML versions. 